\title{
CUSTOMER RELATIONSHIP MANAGEMENT DAN PENGARUHNYA TERHADAP LOYALITAS NASABAH BANK: STUDI PADA BANK MUAMALAT INDONESIA
}

\author{
M. Nur Rianto Al Arif \& Titin Nurasiah \\ UIN Syarif Hidayatullah Jakarta
}

\begin{abstract}
Customer Relationship Management and Its Influence on customer loyalty Bank: A Case Study of Bank Muamalat Indonesia. The aim of this research is to analyze the influence of customer relationship management (CRM) to customer's loyalty. Data collection is using primary and secondary data. The sampling method that used on this research is accidental sampling with 100 respondents. The analysis method on this research is multiple regressions. The CRM variables that used on this research are identify, acquire, retain, develop, and sustainable marketing. From the result, show that the CRM variable had an impact simultaneously on customer's loyalty. Otherwise, only three variables had an impact on customer's loyalty, such as acquire activity, retain, and sustainable marketing. There are also show that only acquire variable had an dominant influence on customer's loyalty in Bank Muamalat Indonesia branch SlipiJakarta, because it has the largest coefficient value.
\end{abstract}

Keywords: Customer Relationship Management, Loyality, Multple Regression

Abstrak. Customer Relationship Management dan Pengaruhnya Terhadap Loyalitas Nasabah Bank : Studi Kasus Pada Bank Muamalat Indonesia. Tujuan dari penelitian ialah untuk menganalisis pengaruh Customer Relationship Management (CRM) terhadap loyalitas nasabah. Pengumpulan data melalui data primer dan sekunder. Penarikan contoh dilakukan dengan teknik sampling aksidental, dengan jumlah responden 100 orang. Metode analisis yang digunakan ialah regresi linear berganda. Variabel CRM yang dipergunakan dalam penelitian ini ialah identify, acquire, retain, develop dan pemasaran yang berkelanjutan. Dari hasil uji regresi linear berganda, variabel CRM (X) berpengaruh secara simultan terhadap peubah loyalitas nasabah. Sedangkan secara parsial hanya tiga variabel yang berpengaruh nyata, yaitu aktivitas acquire, retain dan pemasaran yang berkelanjutan Hal lainnya ditemukan bahwa variabel acquire memiliki pengaruh paling dominan terhadap loyalitas nasabah Bank Muamalat Indonesia Kantor Cabang Slipi, karena nilai koefisien regresinya paling besar.

Kata Kunci: Customer Relationship Management, Loyalitas, Regresi Berganda 


\section{PENDAHULUAN}

Perkembangan perekonomian Indonesia, khususnya dalam sektor jasa menciptakan sebuah persaingan, tidak terkecuali pada sektor perbankan. Sektor perbankan saat ini telah mengalami persaingan yang sangat ketat, khususnya perbankan syariah yang beberapa waktu lalu mengadakan Gerakan Ekonomi Syariah (GRES) yang diluncurkan pada tanggal 17 November 2013. Yakin dengan pencanangan Gerakan Ekonomi Syariah (GRES), Bank Indonesia (BI) memperkirakan pertumbuhan perbankan syariah pada 2014 akan berada di atas 35\%. Bank sentral mengaku telah memancangkan tiga kriteria pertumbuhan perbankan syariah mulai dari level pesimistis, moderat, dan optimis. Dari ketiga standar tersebut, level moderat memiliki pertumbuhan rata-rata di angka 35\% (Liputan 6, 2014).

Tabel 1. Lima Bank Syariah berdasarkan Indeks Loyalitas Penabung

\begin{tabular}{ll}
\hline No & \multicolumn{1}{c}{ Nama Bank } \\
\hline 1 & Bank Muamalat Indonesia \\
2 & Bank Syariah Mandiri \\
3 & Bank CIMB Niaga Syariah \\
4 & BCA Syariah \\
5 & Bank Mega Syariah \\
\hline Sumber: Infobank News (2013)
\end{tabular}

Pada saat ini, kecenderungan dunia bisnis termasuk dunia perbankan yang paling terkini adalah menjadikan pelanggan sebagai 'bagian' dari organisasi. Kecenderungan ini seiring dengan perubahan fokus bisnis dari product centric menjadi customer centric karena dari sisi produk sudah semakin sulit untuk mencari diferensiasi produk (Widodo, 2010). Keunggulan produk centric hanya dapat mewujudkan tujuan jangka pendek perusahaan, sedangkan keunggulan dalam customer centric dapat mewujudkan orientasi jangka panjang perusahaan yaitu loyalitas nasabah. Pada tabel 1 dapat dilihat peringkat 5 (lima) Bank Syariah berdasarkan Indeks Loyalitas Penabung berdasarkan hasil survey yang dilakukan MarkPlus Insight 2011. Pada tabel 2 dapat dilihat 10 (sepuluh) Bank Syariah terbaik dalam Pelayanan Prima periode 2013-2014. 
Melihat pada data tabel 1 dan tabel 2 kedudukan Bank Muamalat dalam indeks loyalitas penabung berada di posisi pertama. Selanjutnya pada tabel 2 dalam 10 Bank Syariah Terbaik dalam Pelayanan Prima Periode 2013-2014, Bank Muamalat Indonesia pada tahun 2013 menduduki peringkat pertama kemudian pada tahun 2014 menduduki peringkat keempat.

Tabel 2. Sepuluh Bank Syariah Terbaik dalam Pelayanan Prima

Periode 2013-2014

\section{PERINGKAT}

\begin{tabular}{lll}
\hline $\mathbf{1}$ & Bank Muamalat & Mandiri Syariah \\
$\mathbf{2}$ & Permata Bank Syariah & Permata Bank Syariah \\
$\mathbf{3}$ & Mandiri Syariah & BCA Syariah \\
$\mathbf{4}$ & BCA Syariah & Bank Muamalat \\
$\mathbf{5}$ & CIMB Niaga Syariah & BRISyariah \\
$\mathbf{6}$ & BII Syariah & BTN Syariah \\
$\mathbf{7}$ & BNI Syariah & Bukopin Syariah \\
$\mathbf{8}$ & Danamon Syariah & CIMB Niaga Syariah \\
$\mathbf{9}$ & BRISyariah & OCBC NISP Syariah \\
$\mathbf{1 0}$ & BTN Syariah & BII Syariah
\end{tabular}

Sumber: Majalah Infobank No. 410/mei 2013/Vol. XXXV \& Majalah Infobank No.422/MEI 2014/VOL. XXXVI

Tolak ukur keberhasilan suatu bank, salah satunya bergantung pada ketertarikan nasabah. Semakin banyak nasabah yang tertarik, maka semakin banyak dana yang terhimpun dan diputarkan kembali dengan meraih profitabilitas secara maksimal. Penerapan Customer Relationship Management (selanjutnya disebut CRM) dalam menjalin komunikasi dengan pelanggan dipandang sangat efektif dalam memberikan pelayanan kepada nasabahnya.

CRM memungkinkan bank untuk mendefinisikan dan mengidentifikasi hubungan antara pelanggan dan rumah tangga. Ini adalah langkah pertama dari proses tersebut, yang kemudian harus disebarkan di seluruh perusahaan perbankan perbankan agar dapat memperoleh keuntungan melalui rancangan produk yang lebih 
baik dan perhatian yang lebih besar terhadap pelanggan utama (Olson dan Shi, 2008).

Secara Umum CRM digunakan oleh perusahaan dalam hal ini perbankan adalah untuk aspek Customer Lifetime Value, Servise Excellent, Customer Satisfaction, dan Customer Loyality. Pada penelitian ini penulis tidak akan membahas semua aspek melainkan membatasi CRM untuk Customer Loyality atau Loyalitas Pelanggan/Nasabah saja. Pada penelitian ini peneliti membatasi teori Customer Relationship Management yang digunakan menurut Philip Kotler.

Perumusan masalah dalam penelitian ini ialah sebagai berikut: (a) Bagaimana pengaruh CRM terhadap Loyalitas nasabah pada PT. Bank Muamalat Indonesia Kantor Cabang Slipi? (b) Variabel apakah yang dominan berpengaruh terhadap loyalitas nasabah pada PT. Bank Muamalat Indonesia Kantor Cabang Slipi?

\section{METODOLOGI}

Dalam penelitian ini yang dijadikan populasi adalah seluruh nasabah PT. Bank Muamalat Indonesia Kantor Cabang Slipi yang berjumlah 14.120 nasabah. Sedangkan sampel yang diambil dari penelitian ini adalah sebagian dari nasabah Bank Muamalat Indonesia Kantor Cabang Slipi. Nasabah yang dimaksud adalah nasabah biasa (bukan nasabah prioritas) yang melakukan transaksi di Bank Muamalat Indonesia Kantor Cabang tersebut. Berdasarkan data dari Bank Muamalat Indonesia Kantor Cabang Slipi per tanggal 30 April 2014 tercatat bahwa Bank Muamalat Indonesia Kantor Cabang Slipi memiliki total nasabah sebanyak 14.120. Dengan menggunakan rumus slovin dengan margin of error sebesar 10\% di atas diperoleh hasil 99.296765119 nasabah kemudian dibulatkan menjadi 100 nasabah. Teknik yang digunakan dalam pengambilan sampel adalah dengan menggunakan Accidental Sampling (Sampling Aksidental), teknik penetuan sampel berdasarkan kebetulan, yakni siapa saja yang secara kebetulan bertemu dengan peneliti dan dapat digunakan sebagai sampel, dan layak sebagai sumber data (Rochaety, 2009).

Teknik analisis yang dipergunakan dalam penelitian ini ialah analisis regresi berganda. Analisis regresi adalah salah satu teknik statistik yang dapat digunakan untuk menggambarkan hubungan antara dua variabel atau lebih untuk variabel 
kuantitatif (Rochaety, 2009).

Regresi linier berganda bertujuan menghitung besarnya pengaruh dua atau lebih variabel bebas terhadap satu variabel terikat dan memprediksi variabel terikat dengan menggunakan dua atau lebih variabel bebas.

Adapun persamaan matematis yang dipergunakan dalam penelitian ini ialah:

$$
\mathbf{Y}=\mathbf{X}_{1}+\mathbf{X}_{2}+\mathbf{X}_{3}+\mathbf{X}_{4}+\mathbf{X}_{5}
$$

Dimana:

$\mathrm{Y} \quad=$ variabel dependen (Loyalitas Nasabah)

$\mathrm{X}_{1} \quad=$ Identify

$\mathrm{X}_{2}=$ Acquire

$\mathrm{X}_{3} \quad=$ Retain

$\mathrm{X}_{4}=$ Develop

$\mathrm{X}_{5} \quad=$ Pemasaran yang Berlanjut

Selanjutnya dilakukan pengujian hipotesis baik secara parsial (uji t), simultan (uji F), maupun koefisien determinasi $\left(\mathrm{R}^{2}\right)$. Uji statistik $t$ pada dasarnya menunjukan seberapa jauh pengaruh satu variabel penjelas/independen secara individual dalam menerangkan variasi variabel dependen. Uji simultan dengan uji $F$ ini bertujuan untuk mengetahui pengaruh bersama-sama variabel independen terhadap variabel dependen. Apabila $\mathrm{F}_{\text {hitung }}>\mathrm{F}_{\text {tabel }}$ maka $\mathrm{H}_{\mathrm{o}}$ ditolak dan $\mathrm{H}_{\mathrm{a}}$ diterima, artinya variabel independen secara simultan mempunyai pengaruh yang signifikan terhadapa variabel dependen. Koefisien determinasi $\left(R^{2}\right)$ pada intinya mengukur seberapa jauh kemampuan model dalam menerangkan variasi variabel dependen.

Untuk melakukan pengujian hipotesis, maka ada beberapa ketentuan yang perlu diperhatikan yaitu merumuskan hipotesis nol $\left(\mathrm{H}_{\mathrm{o}}\right)$ dan harus disertai dengan hipotesis alternative $\left(\mathrm{H}_{\mathrm{a}}\right)$, seperti yang tercantum di bawah ini:

Hipotesis Pertama. 
$\mathrm{H}_{\mathrm{o}} \rightarrow$ secara bersama-sama tidak terdapat pengaruh yang signifikan antara variabel $\mathrm{X}_{1}, \mathrm{X}_{2}, \mathrm{X}_{3}, \mathrm{X}_{4}, \mathrm{X}_{5}$ terhadap variabel $\mathrm{Y}$

$\mathrm{H}_{\mathrm{a}} \rightarrow$ secara bersama-sama terdapat pengaruh yang signifikan antara variabel $\mathrm{X}_{1}, \mathrm{X}_{2}, \mathrm{X}_{3}, \mathrm{X}_{4}, \mathrm{X}_{5}$ terhadap variabel $\mathrm{Y}$

Hipotesis Kedua

$\mathrm{H}_{\mathrm{o}} \rightarrow$ tidak terdapat pengaruh yang signifikan antara variabel $\mathrm{X}_{1}$ terhadap variabel $Y$

$\mathrm{H}_{\mathrm{a}} \rightarrow$ terdapat pengaruh yang signifikan antara variabel $\mathrm{X}_{1}$ terhadap variabel Y

Hipotesis Ketiga

$\mathrm{H}_{\mathrm{o}} \rightarrow$ tidak terdapat pengaruh yang signifikan antara variabel $\mathrm{X}_{2}$ terhadap variabel Y

$\mathrm{H}_{\mathrm{a}} \rightarrow$ terdapat pengaruh yang signifikan antara variabel $\mathrm{X}_{2}$ terhadap variabel Y

Hipotesis Keempat

$\mathrm{H}_{\mathrm{o}} \rightarrow$ tidak terdapat pengaruh yang signifikan antara variabel $\mathrm{X}_{3}$ terhadap variabel Y

$\mathrm{H}_{\mathrm{a}} \rightarrow$ terdapat pengaruh yang signifikan antara variabel $\mathrm{X}_{3}$ terhadap variabel Y

Hipotesis Kelima

$\mathrm{H}_{\mathrm{o}} \rightarrow$ tidak terdapat pengaruh yang signifikan antara variabel $\mathrm{X}_{4}$ terhadap variabel Y

$\mathrm{H}_{\mathrm{a}} \rightarrow$ terdapat pengaruh yang signifikan antara variabel $\mathrm{X}_{4}$ terhadap variabel Y

Hipotesis Keenam

$\mathrm{H}_{\mathrm{o}} \rightarrow$ tidak terdapat pengaruh yang signifikan antara variabel $\mathrm{X}_{5}$ terhadap variabel Y

$\mathrm{H}_{\mathrm{a}} \rightarrow$ terdapat pengaruh yang signifikan antara variabel $\mathrm{X}_{5}$ terhadap variabel Y

\section{PEMBAHASAN}

Uji validitas dilakukan untuk mengetahui sejauhmana pertanyaan yang diajukan dapat mewakili obyek yang diamati, sehingga pertanyaan dalam kuesioner 
memenuhi syarat sah atau tidak untuk dijadikan data primer dalam penelitian. Uji validitas dapat mengkorelasikan masing-masing pertanyaan dengan jumlah skor masing-masing sub variabel. Uji validitas dilakukan dengan menggunakan rumus korelasi Pearson Product Moment dan hasilnya dibandingkan dengan nilai angka kritik tabel korelasi nilai r. Berdasarkan kuesioner yang disebar kepada 20 responden dengan signifikansi 5\%, dari sini di dapat nilai df=n-2, df=20-2=18. Didapatkan angka $r$ tabel $=0.4438$. Jika $r$ ditabel $<\mathrm{r}$ hasil hitungan, maka pernyataan itu valid.

Berdasarkan hasil uji validitas dapat dinyatakan bahwa dari 15 pertanyaan yang diberikan kepada responden adalah valid dan dapat digunakan. Item pertanyaan yang valid penulis anggap sudah terstandarisasi kemudian disebarkan kepada nasabah PT. Bank Muamalat Indonesia Kantor Cabang Slipi sebanyak 100 responden.

Selanjutnya, uji reliabilitas dilakukan untuk mengetahui konsistensi suatu alat pengukuran dalam gejala yang sama. Uji reliabilitas dengan teknik Conbrach's Alpha terhadap kuesioner dinyatakan andal, karena memiliki nilai > 0,6. Berdasarkan hasil pengolahan diperoleh nilai 0, 901 untuk hubungan pelanggan dan 0,863 untuk loyalitas nasabah, sehingga seluruh pertanyaan dapat dinyatakan reliabel untuk memberikan hasil pengukuran yang konsisten.

Berdasarkan olahan data yang telah dilakukan dapat diperoleh model regresi linier berganda berikut:

$$
\mathrm{Y}=2,243+0,482 \mathrm{X}_{1}+0,573 \mathrm{X}_{2}+0,366 \mathrm{X}_{3}+(-0,017) \mathrm{X}_{4}+0,284 \mathrm{X}_{5}
$$

Untuk dapat membaca koefisien regresi yang dimiliki oleh variabel bebas dapat digunakan kolom $t$ dengan membandingkan nilai nyata $t$ hitung lebih besar dari alpha yang ditetapkan $(0,05)$. Jika diperoleh nilai nyata $\mathrm{t}<\alpha(0,05)$, maka $\mathrm{H}_{\mathrm{o}}$ ditolak yang artinya terdapat pengaruh $\mathrm{X}$ terhadap $\mathrm{Y}$.

Berdasarkan hasil olahan data yang diperoleh, maka model regresi linier berganda di atas dapat diinterpretasikan Nilai koefisien konstanta adalah 2,243. Hal ini dapat diartikan, apabila nilai variabel bebas $\left(\mathrm{X}_{2}\right),\left(\mathrm{X}_{3}\right)$, dan $\left(\mathrm{X}_{5}\right)$ konstan, maka besar nilai variabel terikat $(\mathrm{Y})$ menjadi 2,243. Variabel $\mathrm{X}_{2}$ (mendapatkan) atau acquire memiliki tingkat nyata $\mathrm{t}$ hitung 0,047 dengan taraf alpha 0,05. Jika nilai t hitung < 0,05, maka variabel mendapatkan (acquire) ini memiliki pengaruh nyata terhadap 
variabel loyalitas nasabah. Nilai koefisien beta positif 0,573 , diartikan bahwa variabel $\mathrm{X}_{2}$ memiliki pengaruh positif terhadap variabel $\mathrm{Y}$, yaitu jika terjadi peningkatan faktor mendapatkan (acquire) pada CRM, maka akan meningkatkan skor loyalitas nasabah sebesar 0,573 .

Variabel $\mathrm{X}_{3}$ mempertahankan atau retain memiliki tingkat nyata t hitung 0,035 dengan taraf alpha 0,05. Jika nilai $\mathrm{t}$ hitung $<0,05$, maka variabel mempertahankan (retain) ini memiliki pengaruh nyata terhadap variabel loyalitas nasabah.

Nilai koefisien beta positif 0,366 , diartikan bahwa variabel $\mathrm{X}_{3}$ memiliki pengaruh positif terhadap variabel $\mathrm{Y}$, yaitu jika terjadi peningkatan faktor mempertahankan (retain) pada CRM, maka akan meningkatkan skor loyalitas nasabah sebesar 0,366. Variabel $\mathrm{X}_{5}$ (pemasaran yang berkelanjutan), memiliki tingkat nyata t hitung 0,049 dengan taraf alpha 0,05. Jika nilai t hitung $<0,05$, maka variabel pemasaran yang berkelanjutan ini memiliki pengaruh nyata terhadap variabel loyalitas nasabah. Nilai koefisien beta positif 0,284 , diartikan bahwa variabel $\mathrm{X}_{5}$ memiliki pengaruh positif terhadap variabel Y, yaitu jika terjadi peningkatan faktor pemasaran yang berkelanjutan pada CRM, maka akan meningkatkan skor loyalitas nasabah sebesar 0,284 .

Nilai Adjusted R Square = 0,384 dapat dikatakan bahwa 38,4\%. Hal ini berarti bahwa variabel identify $\left(\mathrm{X}_{1}\right)$, acquire $\left(\mathrm{X}_{2}\right)$, retain $\left(\mathrm{X}_{3}\right)$, develop $\left(\mathrm{X}_{4}\right)$, dan pemasaran yang berkelanjutan $\left(\mathrm{X}_{5}\right)$ memiliki kontribusi sebesar $42 \%$ terhadap loyalitas nasabah (Y), sedangkan sisanya 61,6\% (100\%-38,4\%) dijelaskan oleh variabel lain di luar variabel yang digunakan atau dipengaruhi oleh faktor lain seperti membangun database pelanggan yang kuat, membuat profil dari setiap pelanggan, analisis profitabilitas dari tiap-tiap pelanggan, dan interaksi dengan pelanggan yang lebih dikhususkan dan customized. Adapun nilai $\mathrm{R}=0,644$ menunjukkan bahwa antara identfy $\left(\mathrm{X}_{1}\right)$, acquire $\left(\mathrm{X}_{2}\right)$, retain $\left(\mathrm{X}_{3}\right)$, develop $\left(\mathrm{X}_{4}\right)$, dan pemasaran yang berkelanjutan $\left(\mathrm{X}_{5}\right)$ mempunyai hubungan yang sangat kuat terhadap loyalitas pelanggan/nasabah (Y).

Koefisien regresi dari variabel tingkat identfy terhadap loyaitas nasabah adalah sebesar 0,482 dengan nilai t hitung sebesar 1,272< dari t tabel 1,986 dengan tingkat signifikansi sebesar $0,206>$ dari 0,05. Berdasarkan hal tersebut dapat 
disimpulkan bahwa tingkat identify tidak memiliki pengaruh signifikan terhadap loyalitas nasabah. Tanda positif koefisien regresinya menunjukkan bahwa apabila identify meningkat maka loyalitas nasabah juga akan meningkat.

Secara teoritis seharusnya tingkat identify yang dalam penelitian ini dapat menjadi pertimbangan bank syariah untuk meningkatkan loyalitas nasabah, karena di dalamnya mengandung informasi data diri nasabah tersebut yang telah dilakukan pada masa awal pembukaan rekening. Informasi tersebut diharapkan dapat menjadi pertimbangan untuk melihat calon nasabah yang akan bertransaksi di bank tersebut. Akan tetapi hasil penelitian ini menunjukkan bahwa para nasabah tidak merespon secara positif terhadap perlakuan identify yang dilakukan pihak bank yaitu nasabah melakukan pengisian form pendaftaran saat registrasi pembukaan rekening. Hasil ini sama dengan yang dilakukan oleh Syaiful Anwar (2011). Variabel identify tidak berpengaruh nyata terhadap loyalitas nasabah dikarenakan pada penelitian ini tidak menggunakan sampel atau responden nasabah prioritas. Diharapkan pada pihak bank mampu mengefektifkan penggunaan database untuk lebih mengenal nasabahnya, menentukan segmen nasabah dan mampu memenuhi keinginan nasabahnya.

Koefisien regresi dari variabel tingkat acquire terhadap tingkat loyalitas nasabah adalah sebesar 0,573 dengan nilai t hitung sebesar 2,015 > dari t tabel 1,986 dengan tingkat signifikansi sebesar 0,047 < dari 0,05. Berdasarkan hal tersebut dapat disimpulkan bahwa variable acquire memiliki pengaruh yang signifikan terhadap tingkat loyalitas nasabah. Tanda positif koefisien regresinya menunjukkan bahwa apabila acquire meningkat maka loyalitas nasabah juga akan meningkat. Dari hasil pengujian diketahui bahwa tingkat acquire memiliki pengaruh signifikan terhadap loyalitas nasabah. Hasil ini mendukung teori CRM yang terdiri dari identify, acquire, retain, dan develop menurut Philip Kotler mempunyai pengaruh dalam meningkatkan loyalitas nasabah.

Hasil ini berbeda dengan penelitian sebelumnya yang dilakukan oleh Syaiful Anwar (2011) yang menghasilkan variabel acquire tidak berpengaruh terhadap loyalitas nasabah. Sedangkan pada penelitian yang penulis lakukan sekarang, variabel acquire (memdapatkan) berpengaruh terhadap tingkat loyalitas nasabah. Hal ini 
dikarenakan indikator pada variabel acquire berupa BMI menawarkan banyak hadiah langsung dan tidak langsung pada periode waktu tertentu tersebut berupa dengan mengadakan program MBR (Muamalat Berbagi Rezeki) yaitu sebuah program hadiah muamalat berbagi rezeki untuk nasabah yang saldo rata-rata tabungan berada di atas nominal Rp. 3 juta rupiah.

Program ini ternyata mendapat apresiasi baik dari nasabah yang ingin mengikuti program ini sehingga hasil dari penelitian ini variabel acquire berpengaruh terhadap loyalitas nasabah. Koefisien regresi dari variabel tingkat retain terhadap tingkat loyalitas nasabah adalah sebesar 0,366 dengan nilai $t$ hitung sebesar 2,140 > dari t tabel 1,986 dengan tingkat signifikansi sebesar 0,035 < dari 0,05.

Berdasarkan hal tersebut dapat disimpulkan bahwa variabel retain memiliki pengaruh yang signifikan terhadap tingkat loyalitas nasabah. Hasil penelitian ini sesuai dengan asumsi semula bahwa retain akan berpengaruh signifikan terhadap tingkat loyalitas nasabah. Variabel retain merupakan variabel yang paling dominan mempengaruhi loyalitas nasabah Bank Muamalat cabang Slipi, maka pihak bank seharusnya memperhatikan setiap mutu layanan yang diberikan, serta harus lebih ditingkatkan lagi melalui peningkatan mutu SDM.

Hasil ini berbeda dengan penelitian yang dilakukan oleh Syaiful Anwar (2011) yang menghasilkan bahwa variabel retain tidak mempunyai pengaruh terhadap loyalitas nasabah. Sedangkan penelitian yang dilakukan oleh penulis menghasilkan variabel retain memiliki pengaruh yang paling dominan terhadap loyalitas nasabah. Hal ini dikarenakan performa bank Muamalat pada tahun ini masuk dalam salah satu 10 Bank Syariah Terbaik dalam Pelayanan Prima Periode 2014 yang merupakan hasil penilaian Marketing Riset Indonesia. Bank muamalat menempati peringkat 4 (empat) di bawah Bank Mandiri Syariah, Permata Bank Syariah, dan Bank BCA Syariah.

Koefisien regresi dari variabel tingkat develop terhadap tingkat loyalitas nasabah adalah sebesar $-0,017$ dengan nilai $t$ hitung sebesar $-0,070<$ dari $t$ tabel 1,986 dengan tingkat signifikansi sebesar 0,944> dari 0,05. Berdasarkan hal tersebut dapat disimpulkan bahwa variabel develop tidak memiliki 
pengaruh yang signifikan terhadap tingkat loyalitas nasabah. Peubah aktivitas develop belum dapat memberikan pengaruh yang nyata terhadap loyalitas nasabah, dikarenakan ketersediaan teknologi transaksi belum dimanfaatkan secara maksimal, maka pihak bank seharusnya memberikan informasi yang cukup tentang penggunaan dan manfaat teknologi yang disediakan untuk kemudahan transaksi dan akses.

Hasil penelitian ini berbeda dengan penelitian yang dilakukan oleh Syaiful Anwar (2011) yang menghasilkan variabel develop berpengaruh terhadap loyalitas nasabah. Sedangkan hasil dari penelitian yang dilakukan oleh penulis menghasilkan variabel develop tidak memiliki pengaruh terhadap loyalitas nasabah. Ini dikarenakan ada sebagian nasabah tidak menggunakan fasilitas yang disediakan oleh Bank Muamalat seperti internet banking, atau mobile banking.

Koefisien regresi dari variabel tingkat pemasaran yang berkelanjutan terhadap tingkat loyalitas nasabah adalah sebesar 0,284 dengan nilai t hitung sebesar 1,998 > dari t tabel 1,986 dengan tingkat signifikansi sebesar 0,049< dari 0,05. Berdasarkan hal tersebut dapat disimpulkan bahwa variabel pemasaran yang berkelanjutan memiliki pengaruh yang signifikan terhadap tingkat loyalitas nasabah. Hasil ini didukung oleh hasil penelitian dari Masyita Suyuthi (2012) yang menghasilkan bahwa pemasaran yang berkelanjutan memiliki pengaruh yang signifikan terhadap tingkat loyalitas nasabah.

\section{KESIMPULAN}

Berdasarkan hasil olahan data menunjukkan bahwa nilai nyata uji $\mathrm{F}$ $(0,000)$ lebih kecil dari nilai alpha yang ditetapkan $(0,05)$, maka diperoleh kesimpulan $\mathrm{H}_{\mathrm{o}}$ ditolak dan $\mathrm{H}_{1}$ diterima, yang berarti aktivitas CRM berupa identify, acquire, retain, develop, dan pemasaran yang berkelanjutan berpengaruh terhadap loyalitas nasabah. Secara simultan terdapat pengaruh nyata variabel CRM terhadap loyalitas nasabah Bank Muamalat Indonesia sebesar 38,4\% dan sisanya $(61,6 \%)$ dijelaskan oleh variabel lain yang tidak diteliti seperti membangun database pelanggan, analisis profitabilitas dari tiap-tiap pelanggan, dan interaksi dengan pelanggan yang lebih dikhususkan dan customized. Sedangkan secara parsial hanya 3 (tiga) variabel yang mempengaruhi secara nyata, yaitu variabel aktivitas acquire, retain, dan pemasaran yang berkelanjutan dengan nilai koefisien 
regresi sebesar 0,573; 0,366; 0,284. Adapun nilai $\mathrm{R}=0,644$ menunjukkan bahwa antara identify $\left(\mathrm{X}_{1}\right)$, acquire $\left(\mathrm{X}_{2}\right)$, retain $\left(\mathrm{X}_{3}\right)$, develop $\left(\mathrm{X}_{4}\right)$ dan pemasaran yang berkelanjutan $\left(\mathrm{X}_{5}\right)$ mempunyai hubungan yang sangat kuat terhadap loyalitas nasabah (Y).

Variabel yang paling dominan mempengaruhi loyalitas nasabah Bank Muamalat Indonesia cabang Slipi adalah aktivitas acquire dengan nilai koefisien regresi linier berganda paling tinggi yaitu sebesar 0,573.

Berdasarkan hasil penelitian menunjukkan bahwa CRM (identify, acquire, retain, develop dan pemasaran yang berkelanjutan) berperan penting dalam meningkatkan loyalitas nasabah Bank Muamalat Indonesia cabang Slipi. Oleh karena itu, Bank Muamalat Indonesia diharapkan dapat meningkatkan pengenalan nasabah (identify) pengakuisisian nasabah (acquire), mempertahankan nasabah (retain) dan mengembangan sistem informasi dan teknologi (develop) serta pemasaran yang berkelanjutan kepada nasabah Bank Muamalat Indonesia lebih baik lagi.

\section{REFERENSI}

Anwar, Syaiful. 2012. Pengaruh Customer Relationship Management Terhadap Loyalitas Nasabah Bank (Studi pada PT. BNI Syariah Kantor Cabang Fatmawati). (Skripsi Tidak Dipublikasikan). Jakarta: Universitas Islam Negeri Syarif Hidayatullah Jakarta.

Aurora, Uthami Ardha Dara. 2012. Pengaruh Customer Relationship Management Terhadap Loyalitas Pelanggan Kartu Halo. (Skripsi Tidak Dipublikasikan). Depok: Universitas Indonesia.

Gaffar F, Vanessa. 2007. CRM dan MPR Hotel. Bandung: Alfabeta.

Ghozali, Imam. 2006. Aplikasi Analisis Multivariate dengan Program SPSS. Semarang: Badan Penerbit Universitas Diponegoro.

Griffin, Jill. 2002. Customer Loyalty How to Earn It, How to Keep It. Kentucky:McGrawHill.

Griffin, Jill. 2005. Customer Loyalty : Menumbuhkan Dan Mempertahankan Kesetiaan Pelanggan. Jakarta: Erlangga.

Hadinata, Melisa. 2013. Studi Pengaruh Trust, Commitment, Communication, Conflict, Handling terhadap Customer Loyalty di Bank Mandiri 
Surabaya. Jurnal Ilmiah Mahasiswa Universitas Surabaya Vol. 2 No 1, 2013.

Hurriyati, Ratih. 2005. Bauran Pemasaran dan Loyalitas Konsumen. Bandung: Alfabeta.

Infobank News, "Peringkat 5 Bank Syariah berdasarkan Indeks Loyalitas Penabung". Artikel ini diakses pada tanggal 23 Desember 2013 dari www.infobanknews.com/2012/03/peringkat-5-bank-syariah-berdasarkanindeks-loyalitas-penabung/

Irawan, Handi. 2004. 10 Prinsip Kepuasan Nasabah, cetakan kelima, Jakarta: Elex Media Komputindo.

Kotler, Philip dan G Amstong. 2003. Dasar-dasar Pemasaran. Jakarta: PT Indeks Gramedia.

Kotler, Philip dan Keller, Kevin Lane. 2007. Manajemen Pemasaran.. Jakarta: PT. Indeks.

Liputat 6, "Industri Perbankan Syariah Percaya Diri Hadapi 2014", artikel diakses pada $17 \quad$ Desember 2013 dari http://m.liputan6.com/bisnis/read/735054/industri-perbankan-syariahpercaya-diri-hadapi-2014

Lovelock, Christopher dan L.K. Wright. 2005. Manajemen Pemasaran Jasa. Jakarta: Indeks.

Mustafa, Edwin dan Hardius Usman. 2007. Proses Penelitian Kuantitatif. Jakarta: Fakultas Ekonomi Universitas Indonesia.

Oesman, Yeris Marty. 2010. Sukses Mengelola Marketing Mix, CRM, Customer Value \& Customer Dependency. Bandung: Alfabeta.

Rambat, Lupiyoadi. 2006. Manajemen Pemasaran Jasa. Jakarta: Salemba Empat.

Rochaety, Eti, dkk. 2009. Metodologi Penelitian Bisnis: Dengan Aplikasi SPSS. Jakarta: Penerbit Mitra Wacana Media.

Santoso, Singgih dan Fandy Tjiptono. 2001. Riset Pemasaran. Jakarta: Elex Media Computindo.

Siahaan, Hotlan. 2008. Customer Relationship Management (CRM) Sebagai Sarana Meraih Image Positif Untuk Perpustakaan. Jurnal Studi perpustakaan dan 
Informasi Vol. 4 No. 2, 2008.

Sugiyono. 2008. Metode Penelitian Kuantitatif dan Kualitatif. Bandung: Alfabeta.

Suyuthi, Masyita. 2012. Analisis Pengaruh Customer Relationship Terhadap Loyalitas Nasabah Pada PT Bank Sulselbar di Makasar. Makasar: Universitas Hasanudin.

Tjiptono, F. 2007. Pemasaran Jasa. Malang: Bayumedia.

Umar, Husein. 2002. Metode Riset Bisnis. Jakarta: PT Gramedia Pustaka Utama. 